\title{
A case report of cutaneous larva migrans in Argentina
}

\author{
Javier Bava ${ }^{1}$, Lucia G Gonzalez ${ }^{2}$, Celeste M Seley ${ }^{2}$, Gisela P López ${ }^{2}$, Alcides Troncoso ${ }^{1,2 *}$ \\ ${ }^{1}$ Infectious Diseases "Francisco J Muñ $i "$ \\ ${ }^{2}$ Department of Microbiology, Parasitology, Infectious Diseases and Tropical Medicine, School of Medicine, Buenos Aires University, Buenos Aires, \\ Argentina
}

\section{ARTICLE INFO}

Article history:

Received 2 September 2010

Received in revised form 27 September 2010

Accepted 15 Octorber 2010

Available online 1 February 2011

\section{Keywords:}

Cutaneous larva migrans

Epidermal parasitic skin diseases

Dog faeces

Hookworm larvae

Protective footwear

\section{ABSTRACT}

Cutaneous larva migrans (CLM) represents the most common tropically acquired dermatosis. CLM is caused by infection with hookworm larvae in tropical and sub-tropical areas, and people who have a history of foreign travel and of walking barefoot on sandy soil or beaches are at a high risk of getting infected with it. The diagnosis is usually made on the basis of the typical appearance of the lesion, intense itching and history of foreign travel. CLM is a common parasitic skin disease that can be easily prevented by wearing 'protective' footwear. A case of CLM is described in this article.

\section{Introduction}

Cutaneous larva migrans (CLM) is caused by infection with hookworm larvae in tropical and sub-tropical areas and people who have a history of foreign travel and of walking barefoot on sandy soil or beaches are at a high risk of getting infected with it[1]. CLM, with characteristics of skin changes, is usually caused by penetration of larvae from intestinal nematodes originating from animals[2]. Because of biogeographical conditions this disease often affects travellers returning from warm climate countries[3].

\section{Case report}

A 33-year-old female patient was admitted to our Department of Infectious Diseases because of skin changes localized to the left foot. Within one week after returning from holidays in Brazil the patient had noticed the rapid occurrence of creeping changes on the left foot

\footnotetext{
*Corresponding author: Prof. Alcides Troncoso M.D., Ph.D., Department of Infectious Diseases, Bartolome Mitre 1906, CP: 1039-Buenos Aires, Argentina.

E-mail: microbiologiayparasitologia@yahoo.com.ar
}

with concomitant pruritus. Examination revealed a typical serpiginous lesion (Figure1) and a diagnosis of CLM was made on clinical grounds. Both the lesion and the itching were cured with oral albendazole (400 mg daily for 5 days) within one week.

\section{Discussion}

Historically, the term 'cutaneous larva migrans' has synonymous meaning with 'creeping eruption' which is caused by animal hookworm larvae, most commonly Ancylostoma braziliense (A. braziliense). However, recently it has been defined as a syndrome caused by the subcutaneous larval migration of many different types of nematodes. When animal hookworm larvae are involved, the disease is called hookworm-related CLM. When humans, dogs and cats are infected percutaneously with larvae of their own host-adapted hookworms, the lesion at the penetration site varies from nil to an erythematous papular or vesicular rash with varying levels of pruritus. The pathognomonic cutaneous sign is described as a linear, or serpentine-like, slightly elevated and erythematous track that moves forward in an irregular pattern. Creeping eruption usually develops 
1-5 days following skin penetration, or even longer in travellers. In most cases, a very intense itchiness develops shortly after skin penetration and is described by patients as very uncomfortable. Pain can also be present[3].

CLM syndrome can be easily misdiagnosed and thus treated incorrectly. In CLM laboratory abnormalities are usually absent. In addition, a skin biopsy is most often non contributory because of migration of larvae through the skin resulting in larvae absence in the large majority of the histopathological specimens[4]. A history of foreign travel and walking barefoot or sitting or lying on the beach is commonly associated with cutaneous larva migrans, which is found in $95 \%$ of the cases[4].

Geographically, the distribution of hookworm associated CLM appears to mirror the geographic distribution of $A$. braziliense. Most reported cases are tourists who frequented beaches in regions where A. braziliense is endemic in dogs and cats. A. braziliense is found along the southeastern Atlantic coast of North America, the Gulf of Mexico and the Caribbean Sea, down to Uruguay in South America, in Africa (South Africa, Somalia, Democratic Republic of Congo, Sierra Leone), Australia and Asia. The disease does not occur after exposure to beaches where A. braziliense is not present, e.g. the Pacific coast of the USA and Mexico[5].

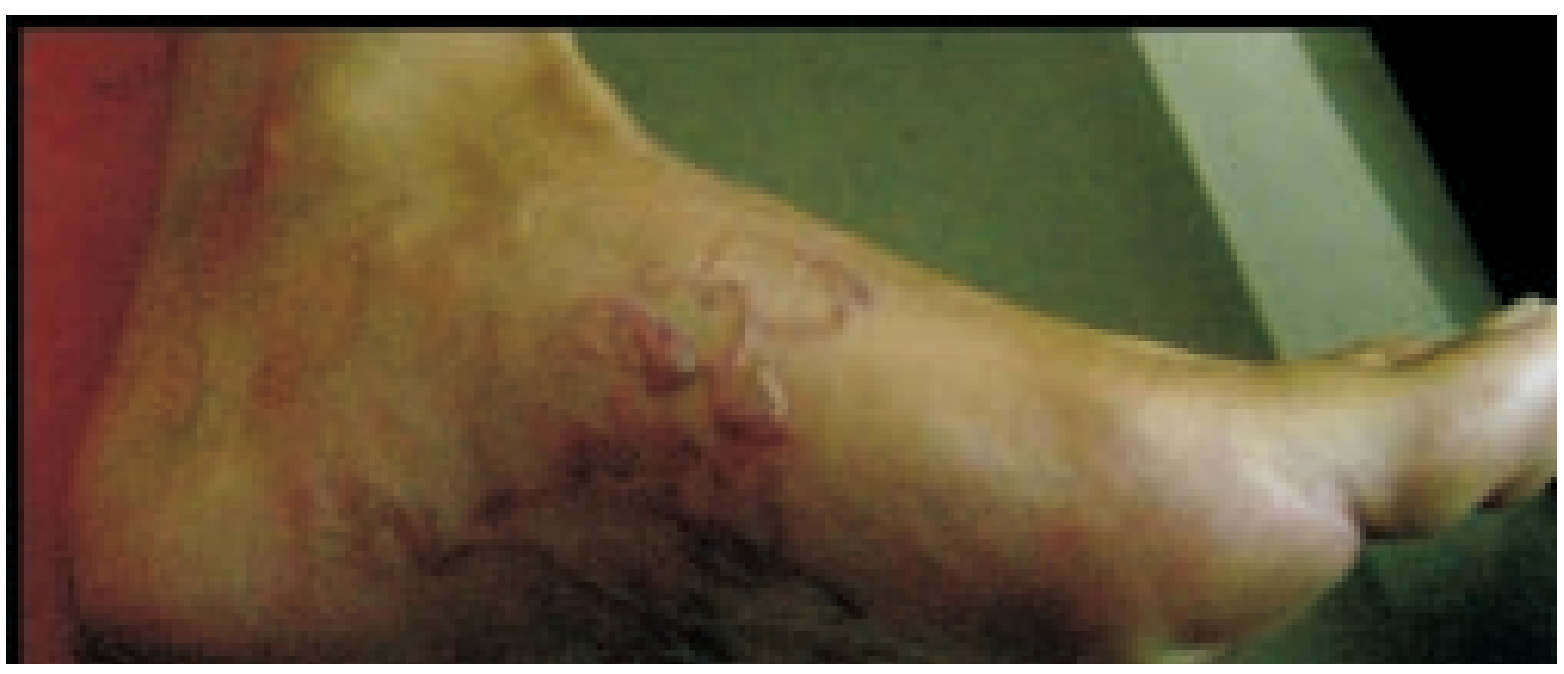

Figure 1. Photograph of left foot taken on date of presentation showing typical serpiginous lesion of cutaneous larva migrans. Photo courtesy of Javier Bava, MD, Ph.D.

To control hookworm-related CLM at the community level, regular treatment of dogs and cats with anthelmintic drugs is necessary, but this is seldom feasible in resourcepoor settings. Animals should be banned from beaches and playgrounds. Tourists are often not aware of the risk for acquiring hookworm-related cutaneous larva migrans when walking barefoot on beaches, or when sunbathing on the beach. Thus, the fact that most cases in tourists acquired it on tropical beach destinations reflects a typical risk behaviour of tourists rather than the true distribution of hookworm larvae in the endemic area[6].

The disease causes discomfort and substantial morbidity. Adequate prevention measures using an integrative approach need to be implemented to reduce the occurrence of hookworm-related CLM. For protection at the individual level, unprotected skin should not come into contact with possibly contaminated soil[7].

\section{Acknowledgements}

We wish to thank Prof. Julian Sloan for her expert opinion and guidance.

\section{Conflict of interest statement}

We declare that we have no conflict of interest.

\section{References}

[1] Hawker J, Begg M, Blair L, Reintjes R, Weinberg J. Communicable disease control handbook. 2nd ed. Oxford: Blackwell; 2006.

[2] Heukelbach J, Feldmeier H. Epidemiological and clinical characteristics of hookworm-related cutaneous larva migrans. Lancet Infect Dis 2008; 8: 302-309.

[3] Brenner MA, Patel MB. Cutaneous larva migrans: the creeping eruption. Cutis 2003; 72: 111-115.

[4] Balfour E, Zalka A, Lazova R. Cutaneous larva migrans with parts of the larva in the epidermis. Cutis 2002; 69: 368-370.

[5] Soo JK, Vega-Lopez F, Stevens HP, Chiodini PL. Cutaneous larva migrans and beyond $-\mathrm{a}$ rare association. Travel Med Infect Dis 2003; 1: 41-43.

[6] Dwight D Bowman. Zoonotic hookworm infections (Ancylostomosis). In: Palmer S, Torgerson SP, DWG Brown, editors. Zoonoses. Oxford Medical Publications; 1998, p. 803-822.

[7] Diba VC, Whitty CJ, Green T. Cutaneous larva migrans acquired in Britain. Clin Exp Dermatol 2004; 29: 555-556. 